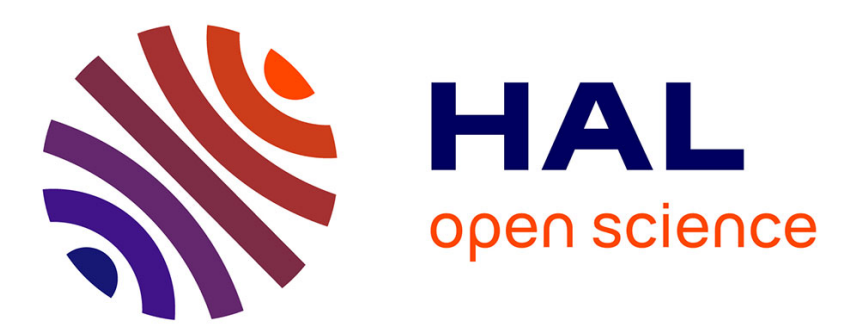

\title{
Investigations on the frequency and temperature effects on mechanical properties of a shape memory polymer (Veriflex)
}

Pauline Butaud, Vincent Placet, Jan Klesa, Morvan Ouisse, Emmanuel Foltete, Xavier Gabrion

\section{To cite this version:}

Pauline Butaud, Vincent Placet, Jan Klesa, Morvan Ouisse, Emmanuel Foltete, et al.. Investigations on the frequency and temperature effects on mechanical properties of a shape memory polymer (Veriflex). Mechanics of Materials, 2015, 87, pp.50-60. hal-02131272

\section{HAL Id: hal-02131272 \\ https://hal.science/hal-02131272}

Submitted on 16 May 2019

HAL is a multi-disciplinary open access archive for the deposit and dissemination of scientific research documents, whether they are published or not. The documents may come from teaching and research institutions in France or abroad, or from public or private research centers.
L'archive ouverte pluridisciplinaire HAL, est destinée au dépôt et à la diffusion de documents scientifiques de niveau recherche, publiés ou non, émanant des établissements d'enseignement et de recherche français ou étrangers, des laboratoires publics ou privés. 


\title{
Investigations on the frequency and temperature effects on mechanical properties of a shape memory polymer (Veriflex)
}

\author{
P. Butaud, V. Placet, J. Klesa, M. Ouisse, E. Foltête and X. Gabrion \\ FEMTO-ST Institute - Department of Applied Mechanics \\ 24, Chemin de l'Epitaphe 25000 Besançon - FRANCE
}

\begin{abstract}
This study proposes a comparison between three identification methods of the mechanical properties of a shape memory polymer (Veriflex ${ }^{\circledR}$ ): quasistatic tensile tests, tensile dynamic mechanical analysis (DMA) and modal tests. The Young's modulus and the Poisson's ratio are determined at ambient temperature using the first technique. The DMA is used to determine the evolution of the viscoelastic properties versus the temperature and the frequency under harmonic loading. The modal analysis is used to identify the viscoelastic properties of the material at higher frequencies. The purpose of this study is to check the validity of the time-temperature equivalence for the Veriflex ${ }^{\circledR}$ obtained from the DMA measurements. It is shown that the viscoelastic properties predicted through the master curve are consistent with the measurements collected using quasi-static and modal test. The aging effect on SMP properties is also quantified.
\end{abstract}

Email address: pauline.butaud@femto-st.fr (P. Butaud) 
Keywords: shape memory polymer, thermo mechanical characterization, time-temperature superposition

\section{Introduction}

Shape memory polymers (SMPs) have the ability to change their shape as a response to an external stimulus [1]. Various stimuli can be used for shape memory activation. The most typical is thermal activation by heating. An overview of other ways of SMP activation can be found in $[2,3,4]$. Experimentally tested working cycle of thermally activated Veriflex ${ }^{\circledR}$ shape memory polymer is presented in Figure 1 (technical details are given in Appendix A). It represents the typical working cycle of a thermally activated SMP. When heated above the glass transition temperature $T_{g}$ (point 1 in Figure 1), it becomes soft and rubbery and its shape can be changed easily. The SMP is then deformed into a temporary shape (point 3) which is fixed during cooling below $T_{g}$ (point 3 to point 4 ). When the maintaining force is released (point 5), the SMP keeps its temporary shape. When heated again above $T_{g}$, the material autonomously returns to its original permanent shape (point 6). The difference between points 1 and 6 represents the SMP residual deformation. Pictures of shape recovery demonstration of this polymer (i.e. return from temporary to permanent shape) are presented in Figure 2. 


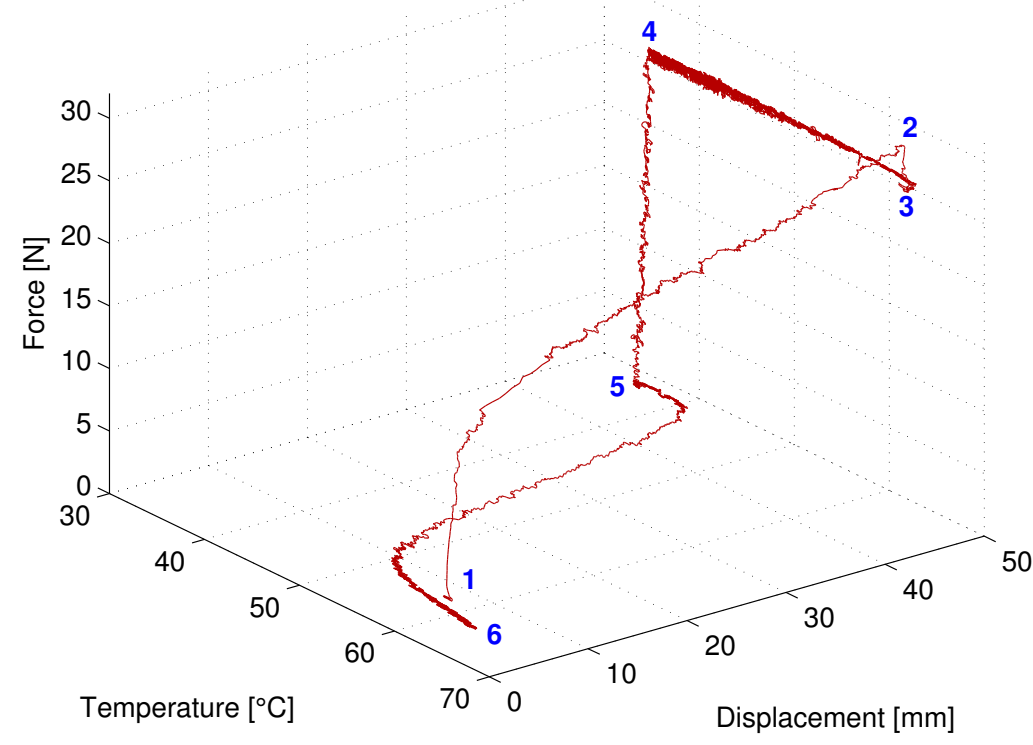

Figure 1: Cyclic thermo-mechanical test of the Veriflex ${ }^{\circledR},(1-3)$ deformation at high temperature, (3-4) fixing temporary shape, (4-5) unloading, (5-6) shape recovery, difference between 1 and 6 is the residual deformation.
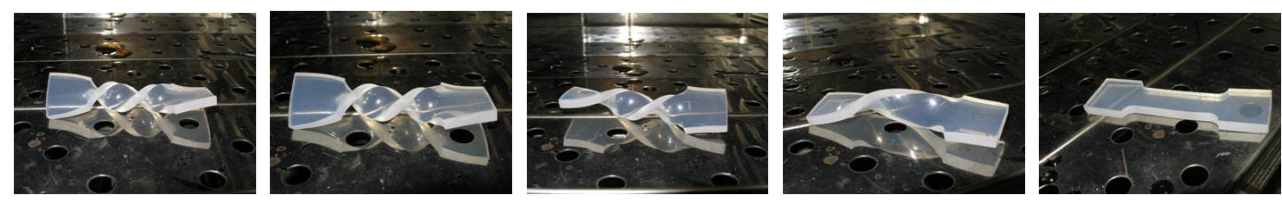

Figure 2: Shape memory demonstration of the Veriflex ${ }^{\circledR}$, the specimen autonomously returns to its original permanent shape when heated at $120^{\circ} \mathrm{C}$.

SMP properties can be used in many applications $[5,6]$. In particular, SMPs offer interesting possibilities in the field of deployable structures, es- 
pecially for space applications, e.g. solar panels or antenas [7]. They reduce complexity of the deployed structure and offer alternative to complicated mechanical systems. The structure can be manufactured in its deployed (permanent) shape and then heated and folded to temporary shape and finally cooled. After reaching the orbit, the structure is heated and deployed to its permanent shape. SMP foam was tested during space shuttle mission STS-134 [8]. SMPs have also potential to be used in self-assembling and self-disassembling structures. Self-folding structures, which are able to transform from sheets to complicated 3D shapes, are presented in [9] and [10]. Self-disassembling structures [11] can be easily dismantled by heating and recycled when their lifetime been completed. The use of SMPs for skin morphing applications is described in [12]. Medical applications of shape memory polymers include e.g. stents [13], intravascular trombectomy device [14], containers for encapsulation of drugs [15] and suture [16].

Veriflex ${ }^{\circledR}$ is a styrene-based SMP available from CRG Industries. Khan et al. [17] studied the mechanical properties and the strain recovery of Veriflex ${ }^{\circledR}$ filled with iron particles and also demonstrated the possibility of inductive heating. Functional fatigue of Veriflex ${ }^{\circledR}$ is described in [18]. Veriflex ${ }^{\circledR}$ SMP was used for the design of various deployable structures like honeycomb, composite wing and self-deploying chair model [19]. The use of Veriflex ${ }^{\circledR}$ for the preparation of composite materials and deployable composite chair is presented in [20]. The accumulation of strain and the recovery ratio of Veriflex ${ }^{\circledR}$ are presented in [21]. The research in the field of Veriflex ${ }^{\circledR}$ SMP at the Department of Applied Mechanics of FEMTO-ST started in 2008. Tests were performed during several years [22]. The work presented here 
is an experimental investigation of the dynamic response of the Veriflex ${ }^{\circledR}$ on a wide frequency band below the glass transition temperature. The experiments outlined in this work explicitly aim to check the validity of the time-temperature equivalence [23] for the Veriflex ${ }^{\circledR}$ obtained from the dynamic mechanical analysis (DMA) measurements, and more exactly to check the capacity of DMA results obtained on a restricted frequency range and at various temperature levels to be used to predict accurately the viscoelastic properties on a wider frequency range. The predicted viscoelastic properties are compared to the measurements collected using quasi-static and modal test. This is an important query considering that measurements combining several experimental methods are particularly time-consuming. The stability of the mechanical properties of the Veriflex ${ }^{\circledR}$ over time was also investigated. The organization of this paper is as follows. The materials and the experimental methods are described in $\S 2$. $\S 3$ shows the results of the three different experimental tests. The complementarity of the results trough the use of a master curve is discussed in $\S 4$. $\S 5$ gives some final conclusions and remarks.

\section{Materials and experimental methods}

\subsection{Materials and specimen preparations}

The styrene-based SMP resin Veriflex ${ }^{\circledR}$ considered hereafter was obtained from CRG Industries, a spin-off company of Cornerstone Research Group, Inc., Dayton, Ohio, USA. The Veriflex ${ }^{\circledR}$ was delivered in two liquid parts. The liquid mixture of the two parts was injected between two glass plates separated by a $4.5 \mathrm{~mm}$ spacer. The polymerisation was then performed by heating, following the curing conditions proposed by CRG Industries, i.e dur- 
ing 9 hours between $75^{\circ} \mathrm{C}$ and $110^{\circ} \mathrm{C}$. The homogeneity of the samples has been found to be a critical point for the description of the behavior of the material [24]. This point has been carefully checked during the elaboration to ensure homogeneity. The obtained thermoset resin plate was finally machined. Dog-bone shaped specimens were produced from the polymer plate for quasi-static tensile tests. The gauge length is $30 \mathrm{~mm}$, and the narrow section is $4.5 \times 15 \mathrm{~mm}$ samples. In the same plate, parallelepipedic samples for DMA testing of $1.95 \times 4.5 \times 110 \mathrm{~mm}$ and a plate for the modal analysis measurements were cut.

\subsection{Mechanical tests}

\subsubsection{Dynamic mechanical analysis}

The frequency dependence of the viscoelastic material's properties is supposed to be described by a complex modulus $E^{*}(\omega)$ :

$$
E^{*}(\omega)=E^{\prime}(\omega)+i E^{\prime \prime}(\omega)=E^{\prime}(\omega)(1+i \tan (\delta))
$$

Viscoelastic properties (storage modulus $E^{\prime}$, loss modulus $E^{\prime \prime}$ and loss factor $\tan (\delta))$ were measured using a Bose Electroforce 3200 apparatus in isothermal conditions between $26^{\circ} \mathrm{C}$ and $75^{\circ} \mathrm{C}$ with steps at $3^{\circ} \mathrm{C}$. The temperature was stabilized during 2 minutes before each measurement to ensure a homogeneous temperature inside the specimen. The heating rate was about $0.1^{\circ} \mathrm{C} / \mathrm{sec}$ between each temperature plateau. The temperature was measured by using a thermocouple placed in a reference sample located in the heating chamber close to the tested specimen. The frequency of the excitation varies from $0.01 \mathrm{~Hz}$ to $10 \mathrm{~Hz}$. The samples were not tested up to $200 \mathrm{~Hz}$, which is the maximum capacity of the Bose Electroforce 3200, in 
order to avoid possible drifts of the results due to the resonance of the machine measured around $70 \mathrm{~Hz}$ [25] for the tested specimen. In order to obtain reliable measurements, the specimens dimensions have been determined to have a ratio of 20 between the stiffness of the sample in the glassy state and the stiffness of the load cell. Effectively, on this DMA apparatus, the load is directly measured using a load sensor and not determined from the actuating system. The compliance of the test set-up was taken into account for the determination of the viscoelastic properties. A sinusoidal tensile load was applied on the sample with a mean amplitude of $0.5 \mathrm{~N}$ and a peak-to-peak amplitude of $0.8 \mathrm{~N}$, in order to test the specimen in the linear viscoelastic range.

\subsubsection{Quasi-static tests}

The quasi-static tensile tests were performed at ambient temperature $21^{\circ} \mathrm{C}\left( \pm 1^{\circ} \mathrm{C}\right)$ using a universal commercial testing machine (Instron 6025) with a capacity of $\pm 100 \mathrm{kN}$. The specimen, clamped using wedge action grips, was subjected to a displacement control feedback at a strain rate of $0.01 \mathrm{~s}^{-1}$. The engineering longitudinal strain was measured by a laser extensometer (EIR LE05) with a displacement accuracy of $1 \mu \mathrm{m}$. The gauge part of the specimen for the strain measurement was $28.6 \mathrm{~mm}$ in length. The longitudinal Young's modulus was determined by a linear regression of the stress-strain curve between $0.01 \%$ and $0.1 \%$ of engineering strain.

\subsubsection{Modal analysis}

A Veriflex ${ }^{\circledR}$ rectangular plate with dimensions $140 \times 110 \times 4.5 \mathrm{~mm}( \pm 0.1 \mathrm{~mm})$ was considered for the modal analysis. The plate was suspended with soft 
springs in order to realize free-free conditions. Contactless actuators and sensors were used. The external force was applied thanks to a voice-coil actuator with a permanent magnet glued at a corner of the plate (Fig. 3a). This assembly was placed in a thermal chamber with a temperature control between $24^{\circ} \mathrm{C}$ and $60^{\circ} \mathrm{C}$ every $10^{\circ} \mathrm{C}\left( \pm 2^{\circ} \mathrm{C}\right)$. A broadband random excitation was applied between 150 and $2000 \mathrm{~Hz}$. The plate response was measured with a laser vibrometer (Polytec OFV-505) successively focused on 24 reflecting stickers spread on the plate (Fig. 3b). The modal frequencies, modal damping coefficients and mode shapes were then identified using Modan` (a homemade modal analysis software) from the measured frequency response functions (FRFs). A finite element model (FEM) at the plate was established on Patran ${ }^{\mathrm{TM}} 2012$ under the hypothesis that the material is homogeneous and isotropic, with a Poisson's ratio $\nu=0.4$ (determined from quasi-static tests), a mass density $\rho=1050 \mathrm{~kg} / \mathrm{m}^{3}$ (determined by measuring the plate's mass and volume) and a presumed Young's modulus. The magnet was included in the numerical model $\left(E=210000 M P a, \nu=0.33, \rho=7460 \mathrm{~kg} / \mathrm{m}^{3}\right)$. Finally a model-test correlation was performed on AESOP ${ }^{\complement}$ software and a model updating procedure allowed to obtain the mechanical parameters of the Veriflex ${ }^{\circledR}$ at the modal frequencies. The same kind of vibration analysis techniques was used by Corn S. et al. [26], but as the inverse identification method is very sensitive to disturbances caused on the structure and not (or badly) taken into account in the model, the voice-coil system actuator was preferred to an impact or a shaker test proposed in [26]. Indeed the hammer is satisfactory to produce the excitation but it excites the suspension modes, and the use of a vibrometer is then difficult. An accelerometer 
can collect measurements when glued on the plate but it induces structural modifications which are difficult to model accurately. Moreover the model updating procedure requires modes pairing between model and test. This necessitates measurements at several points, which could result in significant impact on the dynamic behavior if accelerometers were used. Hence optical measurements are preferred here. The shaker test is very close to the voice-coil actuator, but the slightest misalignment implies the application of couples and parasite transverse forces and the structural modification the load cell quite important and difficult to model correctly. Thus the voice-coil and magnet actuator seems to be a good compromise between experimental feasibility and confidence of results.

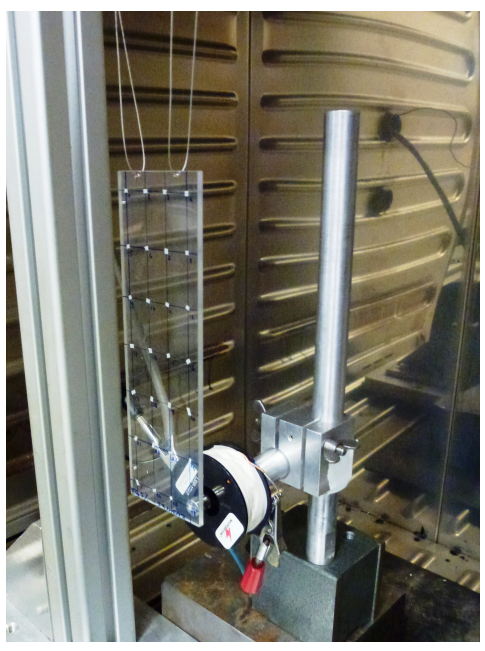

(a)

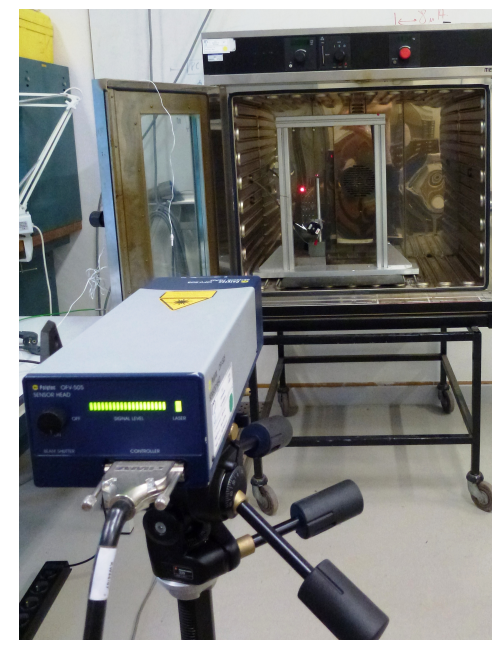

(b)

Figure 3: Modal analysis test device. (a) Magnet-coil excitation system. (b) Laser vibrometer. 


\section{Results}

\subsection{Dynamic mechanical analysis and master curves}

The results of the DMA tests made in 2008 [22] are shown in Figure 4. As expected, and for the tested frequency and temperature ranges, the storage modulus decreases with increasing temperature and increases with increasing frequency. This trend is coherent with the classical behavior of polymeric materials. The storage modulus reaches a maximum value of $1050 \mathrm{MPa}$ at $10 \mathrm{~Hz}$ and for a temperature of $27^{\circ} \mathrm{C}$, it decreases to about ten MPa at

$0.01 \mathrm{~Hz}$ and for a temperature of $75^{\circ} \mathrm{C}$. The loss factor reaches a maximum value of $0.7-0.9$ at the glass transition temperature, which depends on the frequency, between $57^{\circ} \mathrm{C}$ at $0.01 \mathrm{~Hz}$ and $75^{\circ} \mathrm{C}$ at $10 \mathrm{~Hz}$. 

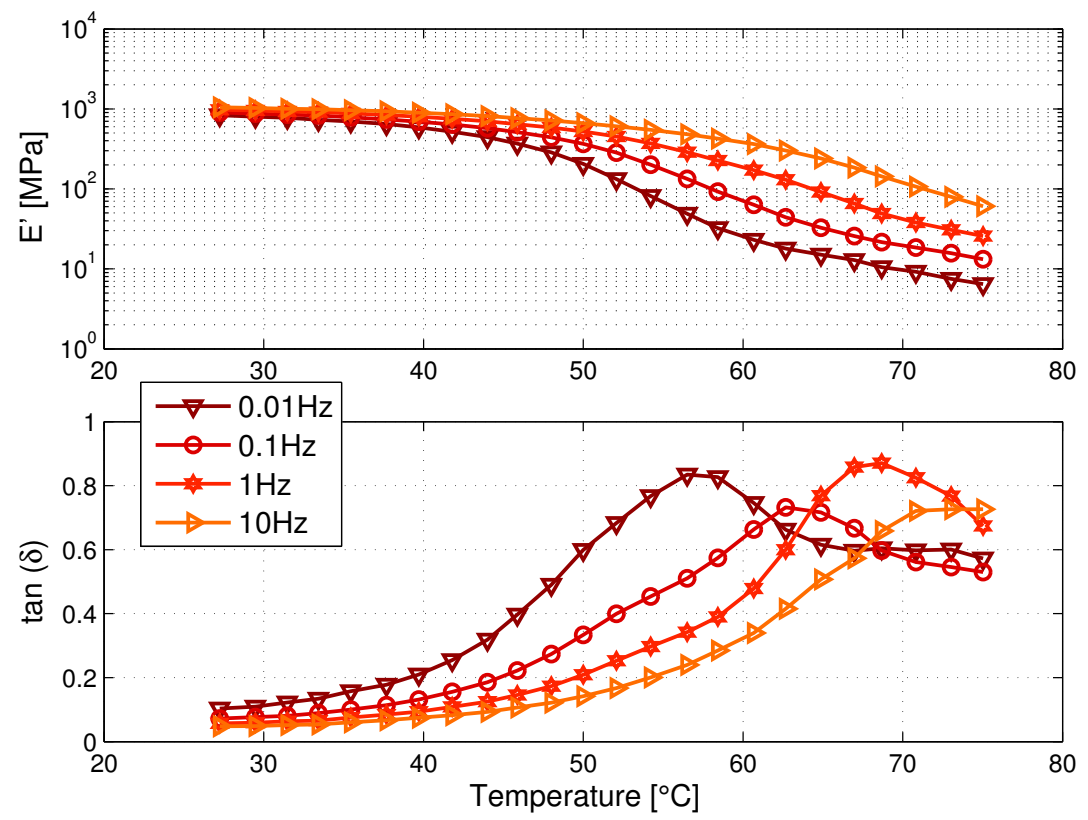

Figure 4: Storage modulus $E^{\prime}$ and loss factor $\tan (\delta)$ measured by DMA in 2008 versus the temperature $T$ and for several frequencies.

In 2012, the aged SMP kept in a drawer during the four years, was tested again. Figure 5 shows the comparison of the mechanical properties of the sample in 2008 and 4 years later measured by DMA at $1 \mathrm{~Hz}$. 

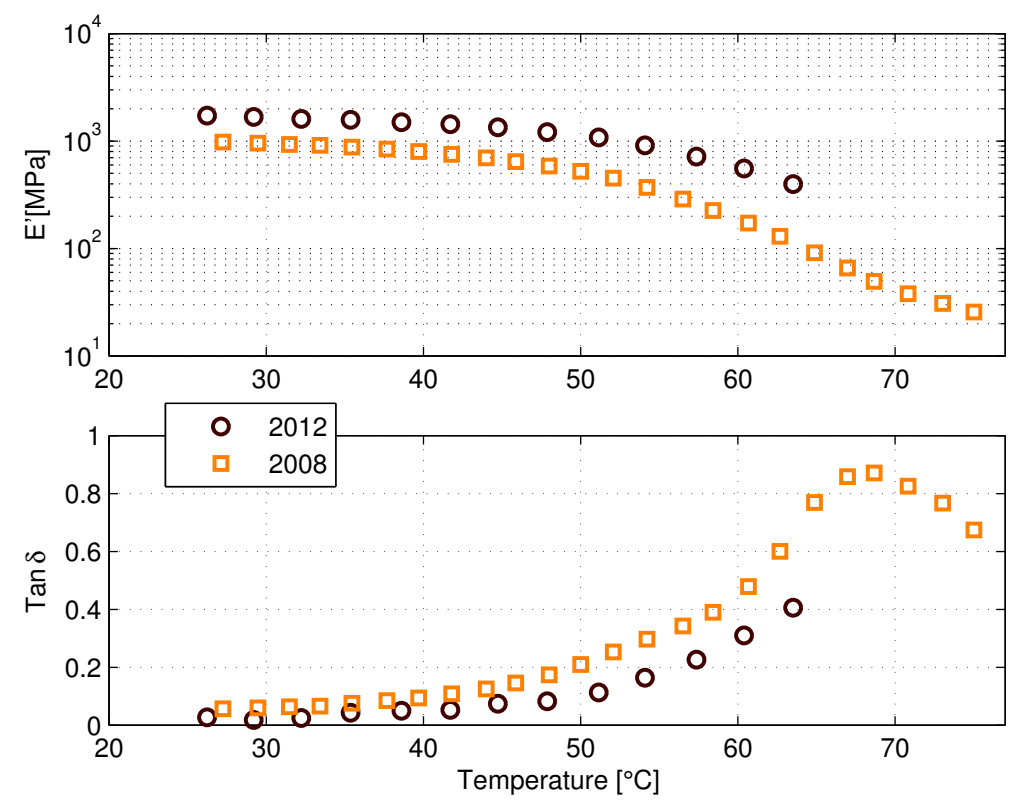

Figure 5: Storage modulus and loss factor at $1 \mathrm{~Hz}$ according to the temperature, 4 years apart.

It can be noticed that the stiffness increased with the time, with a gap of $50 \%$ between the storage moduli measured at 4 years apart. Regarding the loss factor, it decreased with the time. Furthermore, the glass transition temperature seems to have shifted to higher temperatures.

The following study covers only the aged Veriflex ${ }^{\circledR}$ tested below the glass transition temperature. The results of the DMA tests are shown in Figure 6. The storage modulus reaches a maximum value of $1780 \mathrm{MPa}$ at $10 \mathrm{~Hz}$ and for a temperature of $26^{\circ} \mathrm{C}$. 


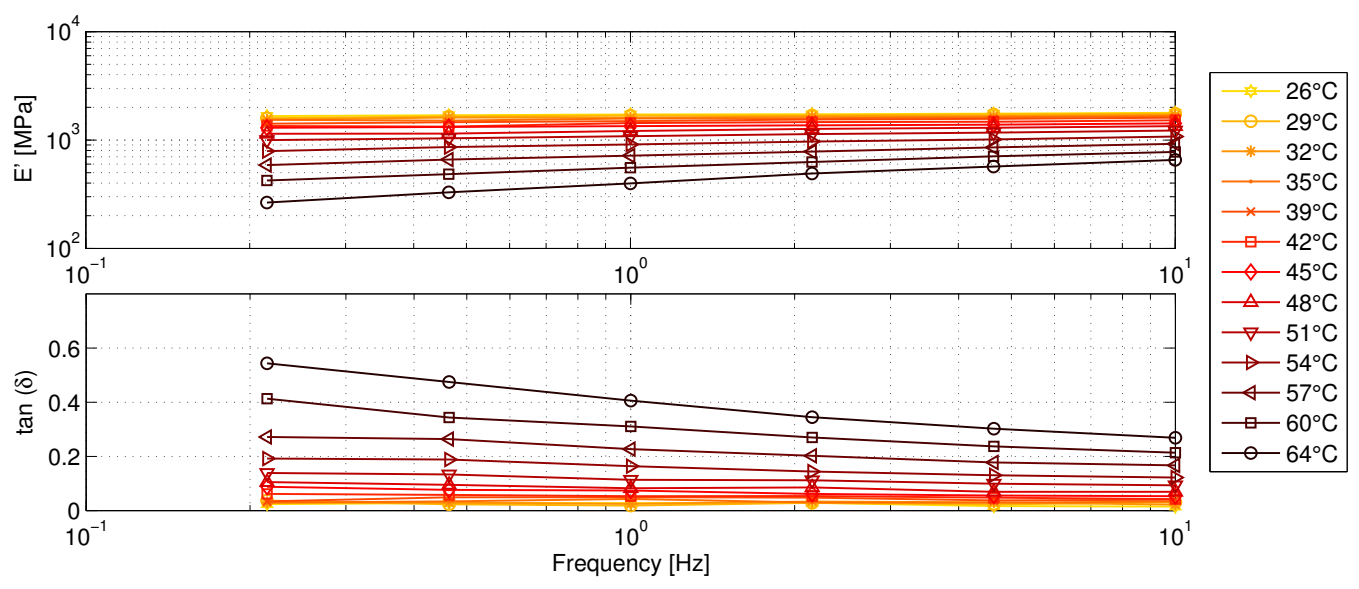

Figure 6: Storage modulus $E^{\prime}$ and loss factor $\tan (\delta)$ measured by DMA according to the frequency $f$ and for several temperatures.

In order to check the validity of the time-temperature superposition, the "Cole-Cole plot" and the "wicket plot" are presented in Figure 7. Figure 7a shows the "Cole-Cole plot", where the loss modulus $E^{\prime \prime}$ is plotted versus the storage modulus $E^{\prime}$. The Figure $7 \mathrm{~b}$ shows the "wicket plot", where the loss angle $\delta$ is plotted versus the modulus amplitude $\left|E^{\star}\right|$. 


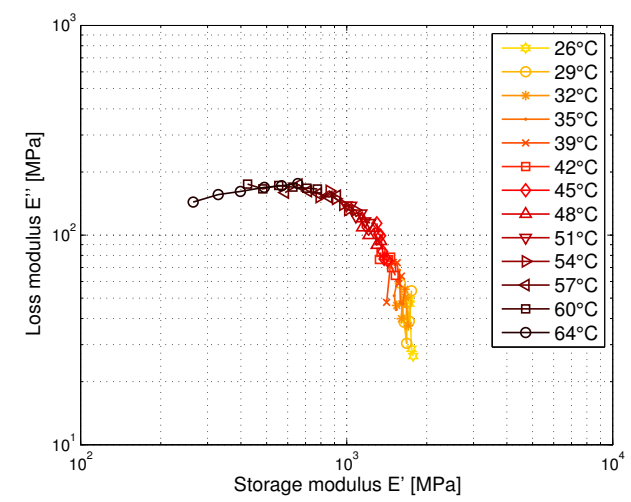

(a)

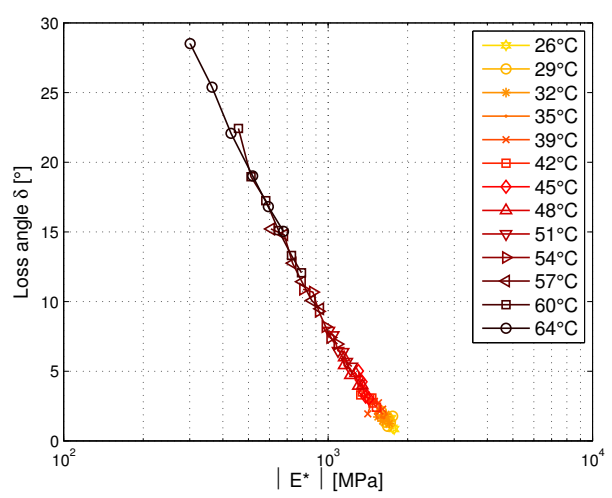

(b)

Figure 7: (a) Cole-Cole and (b) Wicket plot of DMA measurements.

The "wicket plot" [27] and the "Cole-cole plot" [28] are two indicators commonly used to verify the thermo-rheoligical simplicity of the materials. The Figure 7 shows that most of the experimental points lie close to a single curve. This result allows one to conclude that the tBA/PEGDMA is thermorheological simple [29]. Thus the curves of $E^{\prime}$ and $\tan (\delta)$ vs. frequency $f$ (Figure 6) at one temperature can be shifted horizontally to overlap with adjacent curves without vertical shifting because of the thermo-rheological simplicity. The time-temperature superposition shift factors $a_{T}$ used for $E^{\prime}$ must be the same for $\tan (\delta)$ to get time-temperature equivalence [30]. In our case, the shift factors $a_{T}$ are obtained through an optimization procedure (least square technique) for a reference temperature $T_{0}$ selected arbitrarily (the values of $a_{T}$ are given in $\S 4.1 .1$ ). The reference temperature $T_{0}$ for the master curves is $26^{\circ} \mathrm{C}$. The master curves of the storage modulus and loss factor are given in Figure 8. The optimal shift factors are equivalent for both $E^{\prime}$ and $\tan (\delta)$, therefore the time-temperature equivalence is validated in the 
considered temperature and frequency ranges for the Veriflex ${ }^{\circledR}$.

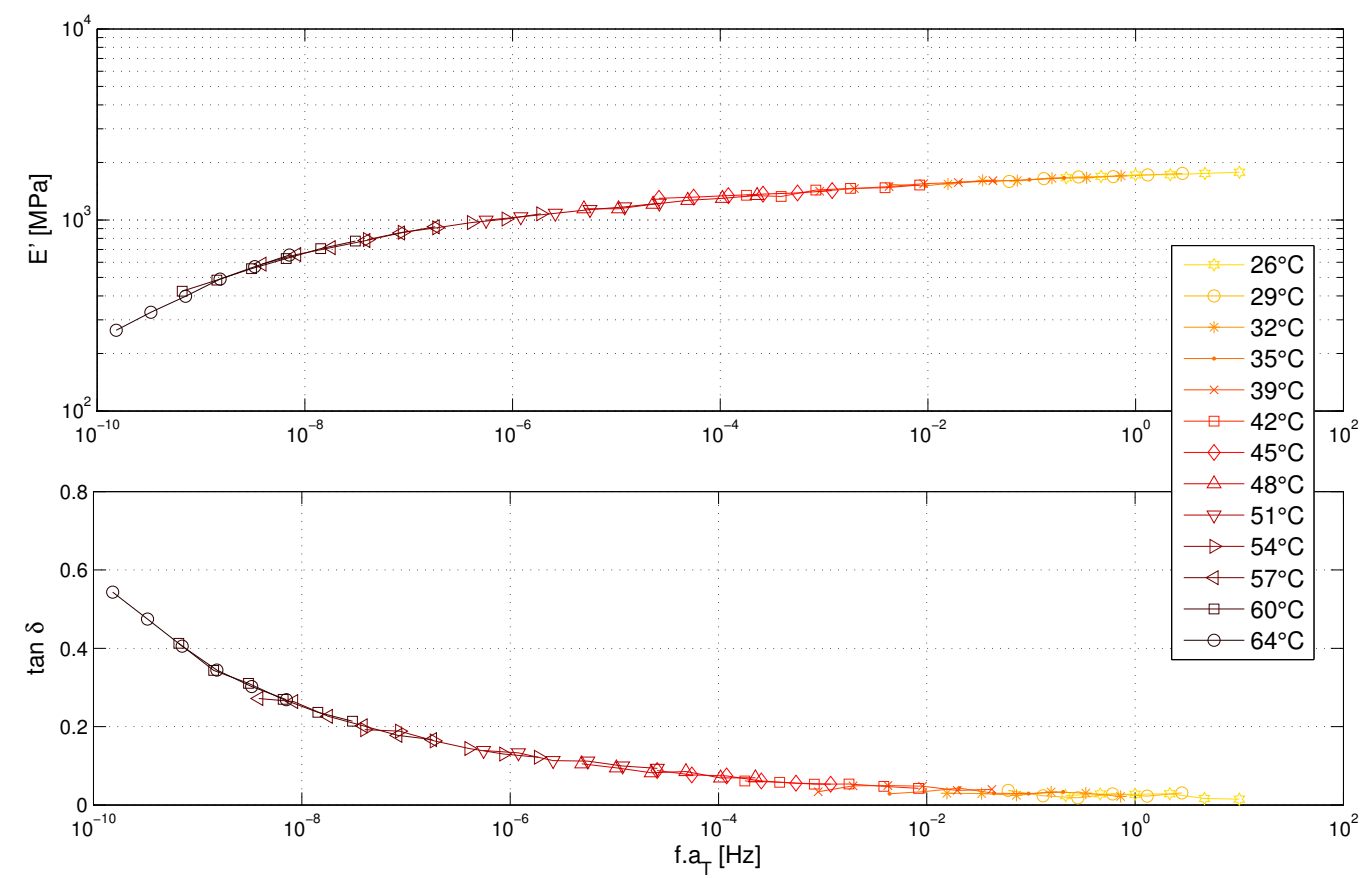

Figure 8: Master curves of E' and $\tan (\delta)$ versus the reduced frequency $f . a_{T}$ with a reference temperature of $26^{\circ} \mathrm{C}$.

\subsection{Quasi-static characterization}

Figure 9a shows the stress-strain curve obtained from the quasi-static test. The apparent Young's modulus is estimated at a value of $1510 \mathrm{MPa}$ for a strain rate of $0.01 \mathrm{~s}^{-1}$. The Poisson's ratio was determined using a contact extensometer glued on the sample, allowing the measurement of the transverse strain. The value is estimated at 0.40 (Figure 9b). 


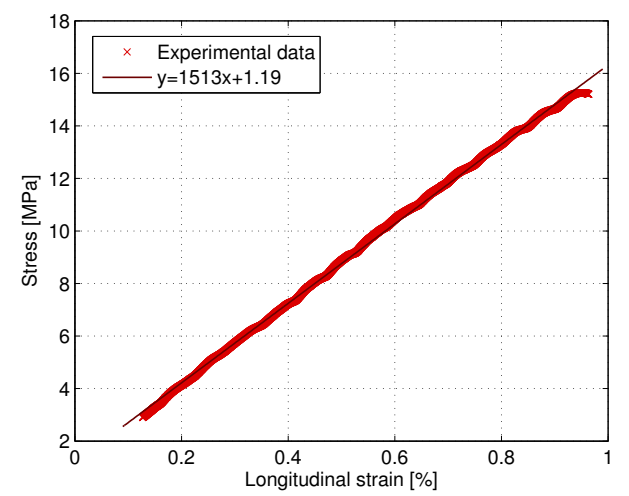

(a)

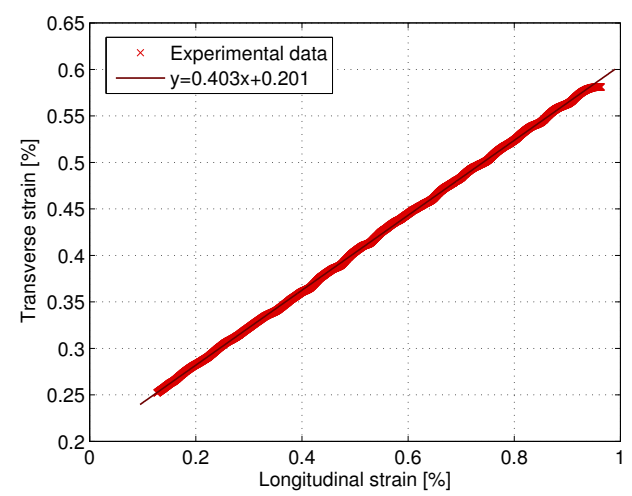

(b)

Figure 9: Quasi-static tensile test at $0.01 \mathrm{~s}^{-1}$ at ambient temperature $\left(21^{\circ} \mathrm{C}\right)$. (a) Stress - strain curve. (b) Transverse strain vs longitudinal strain.

The supplier reports a Young's modulus of $1241 \mathrm{MPa}$ but the test speed to obtain this value is not well informed. Beblo et al. [31] measured a value of $1140 \mathrm{MPa}$ and a Poisson's ratio of 0.48 for a strain rate of $6.10^{-4} \mathrm{~s}^{-1}$. This is coherent with the higher stiffness identified in this work at higher strain rate $\left(10^{-2} s^{-1}\right)[32]$. As far as the Poisson's ratio is concerned, a strain rate dependence has also been noted in the literature $[33,34]$ on polymeric materials and probably explains the difference with the value given by Beblo et al.

\subsection{Modal analysis}

Modal vibration tests allow the identification of the eigen modes of the plate. The MAC (modal assurance criterion) [35] is used to pair experimental and numerical modes, in order to avoid pairing of non-corresponding modes. This phenomenon can occur for example when an experimental mode has not been identified, when a parasitic mode exists in the experimental data, when 
a physical phenomena has been badly represented in the model, or when two modes are crossing because of the existence of some bias in the model... Two modes exhibiting a MAC value higher than 0.7 are considered as paired. Depending on the temperature value, 11 to 13 modes were identified after the model-test correlation (Figure 10).

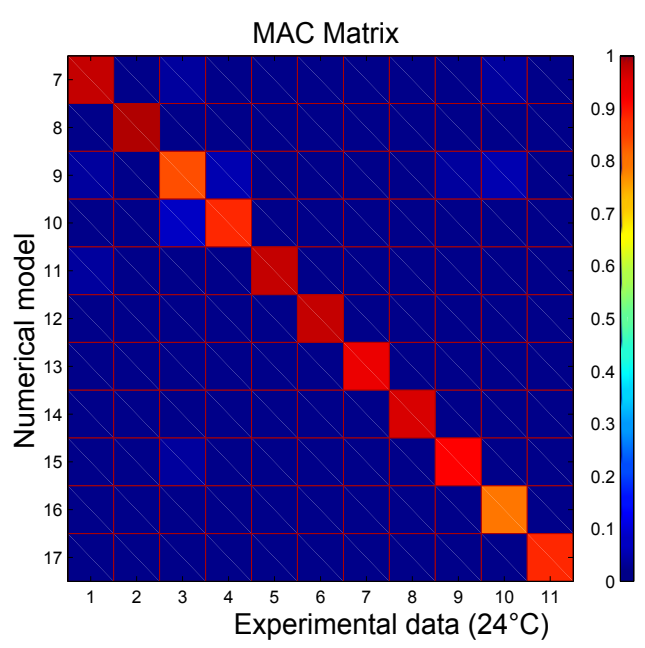

Figure 10: MAC Matrix between numerical eigen modes and experimental ones at $24^{\circ} \mathrm{C}$.

For each mode, the FEM updating procedure gives the value of the storage modulus at the corresponding eigen frequency. The damping ratio $\xi_{j}$ is identified without the use of the model since it is directly related to the real part of the complex value $s_{j}=-\omega_{j} \xi_{j}+i \omega_{j} \sqrt{1-\xi_{j}^{2}}$ ( $\omega_{j}$ being the real eigenvalue) that comes modal identification. Besides, the loss factor is proportional to the damping ratio : $\tan (\delta)=2 \times \xi$. Figure 11 shows the identified storage modulus $E^{\prime}$ and loss factor $\tan (\delta)$ of the Veriflex ${ }^{\circledR}$ from the whole 
set of modal tests.

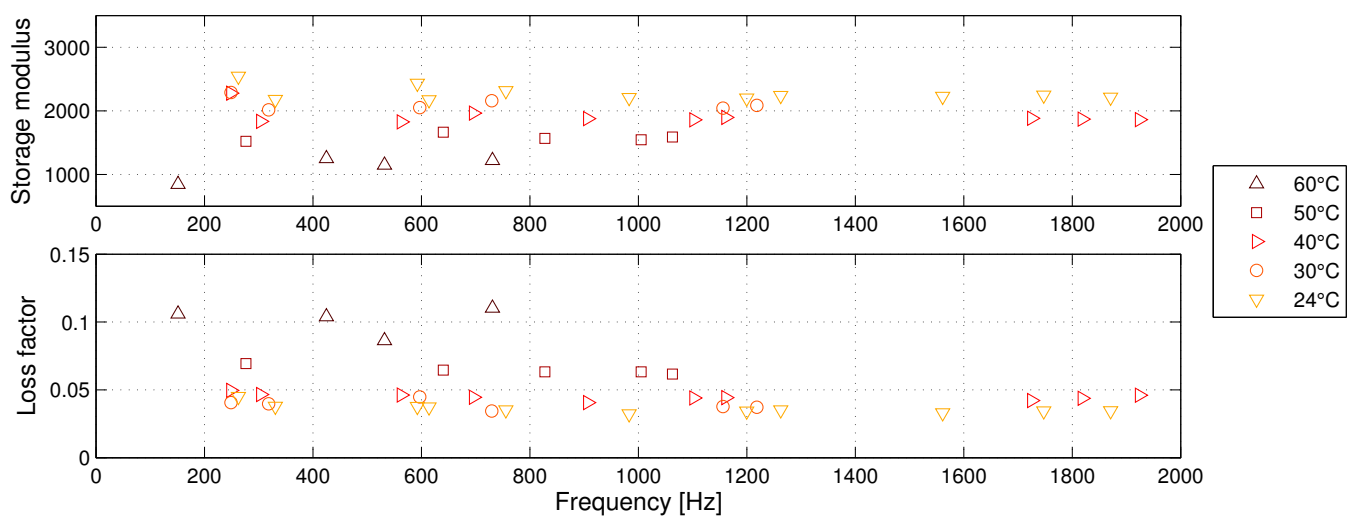

Figure 11: Storage modulus $E^{\prime}$ and loss factor $\tan (\delta)$ identified by modal analysis according to the frequency $f$ and for several temperatures.

The frequency evolution of the mechanical characteristics seem to be a little bit noisy. It should be emphasized that in addition to the uncertainties associated to the experimental procedure, the identification method can also introduce some bias in the results. Two particular points have been investigated: first, the impact of the non-constant thickness of the plate, which varies from $4.36 \mathrm{~mm}$ to $4.58 \mathrm{~mm}$ due to the elaboration process. Secondly, the Poisson's ratio, whose knowledge is necessary for the model updating, is supposed to be frequency independent, its value being given by the quasistatic tests described in section 3.2. A sensitivity analysis allowed to conclude that these two effects, when combined, should not imply a level on uncertainty higher than $4.5 \%$ on the storage modulus, whereas a $10 \%$ decrease in storage modulus is observed. This gap is not well understood yet, even if some other hypotheses are considered. For example, the isotropic character 
of the material is currently under investigation.

\section{Discussion}

\subsection{Methodology}

\subsubsection{Determination of the shift factor temperature dependence}

In order to compare the three kinds of experimental tests, it is necessary to identify the shift factor over the entire tested temperature range and not only on the temperature range of the master curve. The most popular way to obtain $a_{T}(T)$ is the Williams-Landel-Ferry law [36] (or WLF), in which the dependence of the shift factor on temperature is expressed by

$$
\log a_{T}=\frac{-C_{1}^{0}\left(T-T_{0}\right)}{C_{2}^{0}+\left(T-T_{0}\right)},
$$

which can also be written

$$
\frac{T-T_{0}}{\log \left(a_{T}\right)}=-\frac{1}{C_{1}^{0}}\left(T-T_{0}\right)-\frac{C_{1}^{0}}{C_{2}^{0}} .
$$

The Figure 12a shows the "WLF plot", where $\frac{T-T_{0}}{\log \left(a_{T}\right)}$ is plotted as a function of $\left(T-T_{0}\right)$. If the behavior of the Veriflex ${ }^{\circledR}$ followed the WLF law then the experimental data should be close to a single line. As shown is the figure, the WLF law does not seem to be consistent with the data. This is not surprising since the WLF law is known to be valid between $T_{g}$ and $T_{g}+100 K$. Though, it is still possible to estimate the values of the WLF constants by plotting an approximate linear curve. Here the constants were evaluated at $C_{1}^{0}=-21$ and $C_{2}^{0}=-118.7$ for the reference temperature $T_{0}=26^{\circ} \mathrm{C}$. 
Alternatively, the shift factor $a_{T}(T)$ may be obtained through the use of the Arrhenius law [37], expressed by

$$
\log \left(a_{T}\right)=\frac{E_{a}}{R}\left(\frac{1}{T}-\frac{1}{T_{0}}\right),
$$

where $E_{a}$ is the activation energy and $R=8.314 \mathrm{~J} \cdot \mathrm{mol}^{-1} \cdot K^{-1}$ the universal gas constant.

The Figure $12 \mathrm{~b}$ shows $\log \left(a_{T}\right)$ plotted versus $1 / T$. The data are close to a single line therefore the Arrhenius law is adapted for the description of the behavior of the Veriflex ${ }^{\circledR}$. The activation energy was estimated at $E_{a}=220 \mathrm{~kJ} / \mathrm{mol}$, value consistent with the magnitudes of the activation energy of polymeric materials.

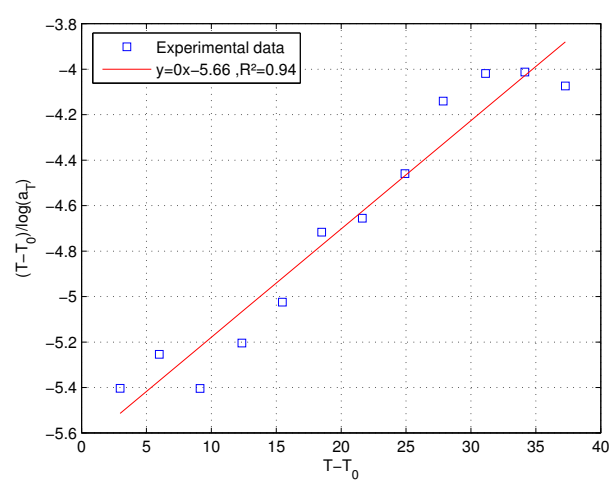

(a)

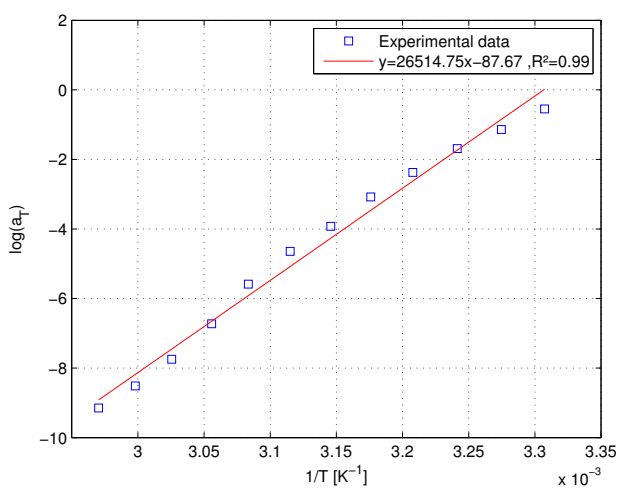

(b)

Figure 12: Shift factor $a_{T}$ : WLF and Arrhenius laws.

The Arrhenius law will be used in the following part to estimate the value of the shift factor $a_{T}(T)$ for the temperature values used for quasi-static and modal tests. 


\subsubsection{Comparison between different methods}

This study intends to compare the master curves obtained with the DMA and the results collected by the modal analysis and the quasi-static tests. The results of quasi-static tests and modal analysis are translated with the shift factor $a_{T}(T)$ and then plotted on Figure 13 with the DMA master curves. To define the frequency of the quasi-static test, the strain rate was taken into account, corresponding to a frequency of $0.01 \mathrm{~Hz}$.
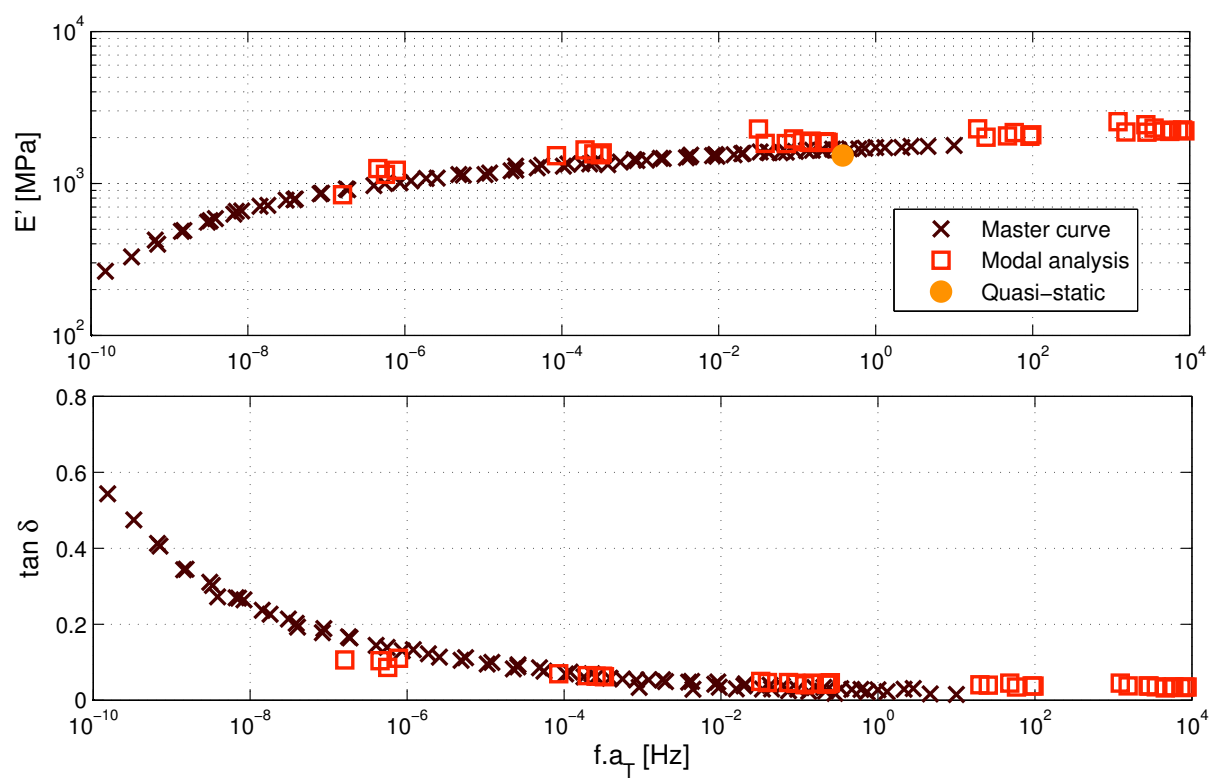

Figure 13: Comparison of the three experimental methods on the storage modulus and the loss factor according to the reduced frequency and for the reference temperature $T_{0}=26{ }^{\circ} \mathrm{C}$.

The time-temperature superposition (TTS) data obtained by DMA are consistent with the quasi-static and modal results for both the storage modulus and the loss factor. The relative distance between the different methods 
is less than $10 \%$ for the storage modulus and less than $20 \%$ for the loss factor. To go further, the results for the Arrhenius law but also for the WLF law are plotted on Figure 14.
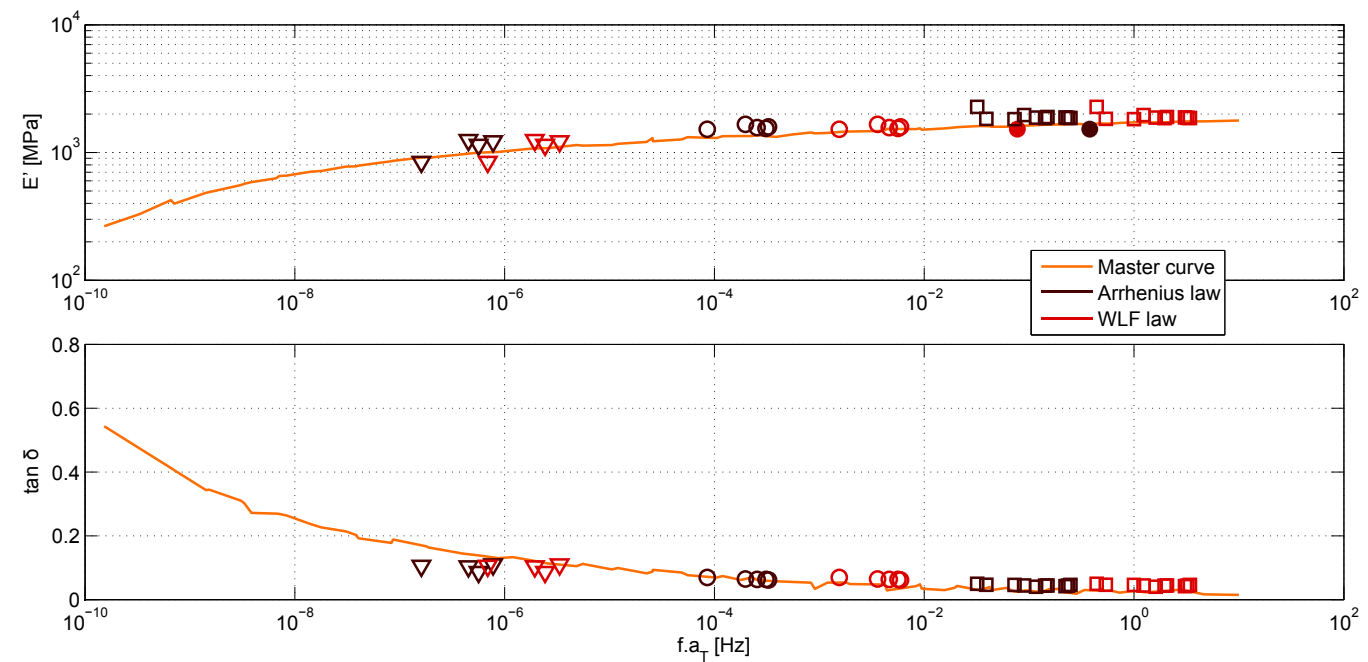

Figure 14: Comparison of the three experimental methods on the storage modulus and the loss factor according to the reduced frequency and for the reference temperature $T_{0}=26^{\circ} \mathrm{C}$ : experimental data from quasi-static tensile test at $21^{\circ} \mathrm{C}(\bullet)$, modal analysis at $40{ }^{\circ} \mathrm{C}(\square)$, at $50^{\circ} \mathrm{C}(\circ)$ and at $60{ }^{\circ} \mathrm{C}(\nabla)$.

The relative distance between the modal analysis at each temperature, the quasi-static test and the master curve is defined by

$$
\frac{1}{n} \sqrt{\sum_{k=1}^{n}\left(\frac{E_{k}^{d m a}-E_{k}^{\text {modal }}}{\frac{E_{k}^{\text {dma }}+E_{k}^{\text {modal }}}{2}}\right)^{2}},
$$

with $n$ the number of frequencies compared (just one for the quasi-static test, five for the modal analysis at $50^{\circ} \mathrm{C}$, four only at $60^{\circ} \mathrm{C} \ldots$ ). 
Figure 15a shows the relative distance on storage modulus. A better correlation between modal-DMA and static-DMA is obtained when the WLF shift factor is used. The trend is the same on loss factor (Figure 15b), except for the tests at $50^{\circ} \mathrm{C}$ where the Arrhenius expressions gives a very good estimation of the damping effects.

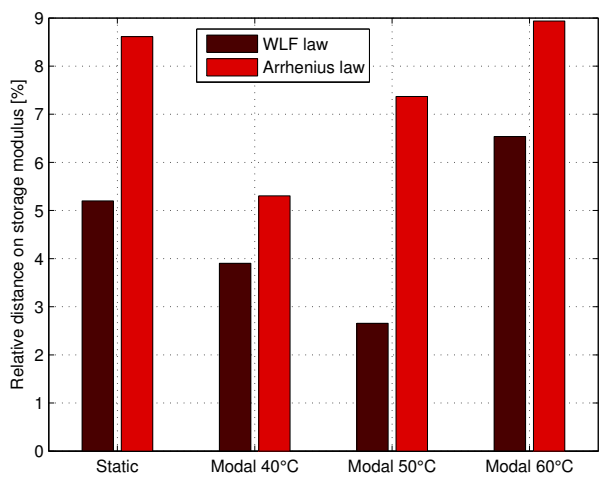

(a)

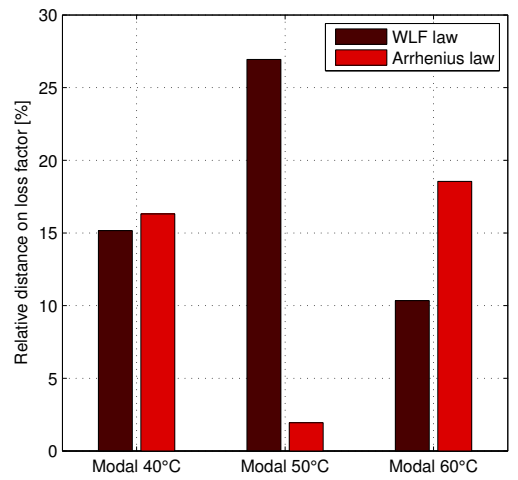

(b)

Figure 15: Relative distance on (a) the storage modulus and (b) the loss factor.

An interesting observation is that the quality of the fit for the Arrhenius law or for the WLF law seen in $\S 4.1 .1$ is not correlated with the quality of the comparison modal-DMA and static-DMA. Indeed the relative distance is almost always lower for the WLF law than for the Arrhenius law.

Depending on the choice of the shift factor expression, the relative distance can reach $9 \%$ for the storage modulus and $27 \%$ for the loss factor. Thus the values estimated using the master curve are approximated. The TTS is a very efficient tool to restrain the range of tests to be performed through the use of master curves, however the levels of uncertainties related to the 
estimation of the dynamical properties at various temperatures/frequencies can be quite large. The levels of variations observed here could yield to significant change on vibration response of a structure made of bulk polymer if excited in modal range.

Furthermore it would be interesting to extend this study to higher temperatures to check the validity of the TTS above the glass transition temperature. However a modal analysis at this temperature range is quite difficult due to the very low stiffness of the Veriflex ${ }^{\circledR}$, so the use of an alternative technique would probably be necessary.

\subsection{Material}

The Veriflex ${ }^{\circledR}$ mechanical properties vary with temperature and frequency. The storage modulus loses two orders of magnitude before and after the glass transition temperature and the loss factor is over 0.6 during the glass transition temperature and may reach 0.9 to a certain temperature and a certain frequency. This material therefore has interesting skills for vibration damping over a wide frequency band. However, ageing effect on Veriflex ${ }^{\circledR}$ has been highlighted in $\S 3.1$ since the alteration of its properties with time has been observed. The physical ageing in plastics is known for many years, indeed the amorphous materials are not in thermodynamic equilibrium at temperatures below their glass transition [38]. The Veriflex ${ }^{\circledR}$ is a thermoset and so it is concerned by these aging aspects. The plate of Veriflex ${ }^{\circledR}$ tested four years apart was stored protected from light but at temperature below its glass transition temperature and so it is consistent that the Young's modulus has increased [39] and the glass transition temperature has decreased [40]. Therefore it seems important in the future to collect data on the ageing of 
the SMPs to not miss information about their mechanical behaviors and to identify and discriminate the degradation mechanisms which are involved.

\section{Conclusion}

Since shape memory polymers are being considered for bio-medicals and structural applications, it is becoming important that their mechanical properties on a wideband of frequencies and their evolution with ageing are well known. The objective of this study was to highlight the time-temperature equivalence by comparing three experimental methods allowing the identification of the storage modulus over frequency and temperature. This equivalence has been checked on a sample tested with a DMA. Quasi-static tests and modal analysis have been carried out to explore a wider frequency band. In the light of this study the TTS seems to be a very efficient tool to restrain the range of tests since the master curve and the results of the quasi-static and the modal tests are quite similar. It is also shown that the Veriflex ${ }^{\circledR}$ is subjected to mechanical properties changes with the time (increasing of the stiffness, and reduction of the $T_{g}$ ) on the same basis as others thermosets.

\section{Acknowledgements}

This work was co-financed by The French National Research Agency under grant number ANR-12-JS09-008-COVIA. It has been performed in cooperation with the Labex ACTION program (ANR-11-LABX-0001-01). 


\section{Appendix A. Technical details about the Shape-Memory Cycle iden- tification}

The shape-memory cycle identification has been performed using a universal commercial testing machine (Instron 6025) with a capacity of $\pm 100 \mathrm{kN}$ in a thermal chamber with a temperature control between $30^{\circ} \mathrm{C}$ and $70^{\circ} \mathrm{C}$ $\left( \pm 2^{\circ} \mathrm{C}\right)$. The temperature was measured using a thermocouple placed in a reference sample located in the heating chamber close to the tested specimen. The gauge length was $45 \mathrm{~mm}$, and the narrow section was $4.5 \times 15 \mathrm{~mm}$. The specimen, clamped using wedge action grips, was heated above its glass transition temperature $T_{g}$, at $65^{\circ} \mathrm{C}$. It was subjected to a displacement control feedback at a rate of $0.2 \mathrm{~mm} / \mathrm{sec}$ to $45 \mathrm{~mm}$. The sample was then cooled under $T_{g}$ in the constant stress of $27 \mathrm{~N}$. It was discharged at $0.2 \mathrm{~N} / \mathrm{sec}$ to $0.5 \mathrm{~N}$ to obtain the stable temporary shape. Finally by increasing the temperature in the thermal chamber, the sample came back to its permanent shape, the transformation temperature was $43^{\circ} \mathrm{C}$ (inflection of the curve). 
[1] D. Ratna, J. Karger-Kocsis, Recent advances in shape memory polymers and composites: a review, Journal of Materials Science 43 (1) (2007) $254-269$.

[2] M. Behl, A. Lendlein, Shape-memory polymers, Materials Today 10 (4) (2007) $20-28$.

[3] L. Sun, W. Huang, Z. Ding, Y. Zhao, C. Wang, H. Purnawali, C. Tang, Stimulus-responsive shape memory materials: A review, Materials \& Design 33 (0) (2012) $577-640$.

[4] C. C. Wang, W. M. Huang, Z. Ding, Y. Zhao, H. Purnawali, Cooling/water-responsive shape memory hybrids, Composites Science and Technology 72 (10) (2012) 1178-1182.

[5] M. Behl, M. Y. Razzaq, A. Lendlein, Multifunctional shape-memory polymers, Advanced Materials 22 (31) (2010) 3388-3410.

[6] B. Dietsch, T. Tong, A review-: Features and benefits of shape memory polymers (smps), Journal of advanced materials 39 (2) (2007) 3-12.

[7] Y. Liu, H. Du, L. Liu, J. Leng, Shape memory polymers and their composites in aerospace applications: a review, Smart Materials and Structures 23 (2) (2014) 023001.

[8] L. Santo, F. Quadrini, G. Mascetti, F. Dolce, V. Zolesi, Mission sts-134: Results of shape memory foam experiment, Acta Astronautica 91 (0) (2013) 333-340. 
[9] Y. Liu, J. K. Boyles, J. Genzer, M. D. Dickey, Self-folding of polymer sheets using local light absorption, Soft Matter 8 (2012) 1764-1769.

[10] S. M. Felton, M. T. Tolley, B. Shin, C. D. Onal, E. D. Demaine, D. Rus, R. J. Wood, Self-folding with shape memory composites, Soft Matter 9 (2013) 7688-7694.

[11] J. Carrell, D. Tate, S. Wang, H.-C. Zhang, Shape memory polymer snap-fits for active disassembly, Journal of Cleaner Production 19 (1718) (2011) $2066-2074$.

[12] C. Thill, J. Etches, I. Bond, K. Potter, P. Weaver, Morphing skins, The Aeronautical Journal 112 (1129) (2008) 117-139.

[13] K. Gall, C. M. Yakacki, Y. Liu, R. Shandas, N. Willett, K. S. Anseth, Thermomechanics of the shape memory effect in polymers for biomedical applications, Journal of Biomedical Materials Research Part A 73 (3) (2005) 339-348.

[14] W. S. IV, T. Wilson, W. Benett, J. Loge, D. Maitland, Laser-activated shape memory polymer intravascular thrombectomy device, Opt. Express 13 (20) (2005) 8204-8213.

[15] R. Fernandes, D. H. Gracias, Self-folding polymeric containers for encapsulation and delivery of drugs, Advanced Drug Delivery Reviews 64 (14) (2012) 1579 - 1589, emerging micro- and nanotechnologies for the development of novel drug delivery devices and systems.

[16] A. Lendlein, R. Langer, Biodegradable, elastic shape-memory polymers 
for potential biomedical applications, Science 296 (5573) (2002) 16731676.

[17] F. Khan, J.-H. Koo, D. Monk, E. Eisbrenner, Characterization of shear deformation and strain recovery behavior in shape memory polymers, Polymer Testing 27 (4) (2008) 498 - 503.

[18] C. Schmidt, K. Neuking, G. Eggeler, Functional Fatigue of Shape Memory Polymers, Advanced Engineering Materials 10 (10) (2008) 922-927.

[19] E. Havens, B. A. Dietsch, T. H. Tong, P. J. Hood, Shape memory polymer nanocomposites: Multifunctional materials for revolutionary applications, Polymer Preprints 46 (1) (2005) 556-557.

[20] J. Ivens, M. Urbanus, C. De Smet, Shape recovery in a thermoset shape memory polymer and its fabric-reinforced composites, EXPRESS Polymer Letters 5 (3) (2011) 254-261.

[21] A. Chowdhury, C. Schmidt, K. Neuking, G. Eggeler, Comparative studies on the accumulation of strain and recovery ratio of veriflex ${ }^{\circledR}$, a shape-memory polymer: infrared and laser experiments, High Performance Polymers 25 (8) (2013) 886-893.

[22] J. Klesa, V. Placet, E. Foltete, M. Collet, Experimental Evaluation of the Rheological Properties of Veriflex Shape Memory Polymer, ESOMAT 2009 - 8th European Symposium on Martensitic Transformations.

[23] G. Swallowe, Time-temperature equivalence, in: Mechanical Properties and Testing of Polymers, Springer, 1999, pp. 249-251. 
[24] N. Liu, Q. Xie, W. Huang, S. Phee, N. Guo, Formation of micro protrusion arrays atop shape memory polymer, Journal of Micromechanics and Microengineering 18 (2) (2008) 027001.

[25] V. Placet, E. Foltête, Is dynamic mechanical analysis (dma) a nonresonance technique?, in: EPJ web of conferences, Vol. 6, EDP Sciences, 2010, p. 41004.

[26] S. Corn, J. S. Dupuy, P. Ienny, L. Daridon, et al., Vibration analysis techniques for detecting filler-matrix decohesion in composites, Revue des composites et des matériaux avancés 22 (1) (2012) 77-90.

[27] M. van Gurp, J. Palmen, Time-temperature superposition for polymeric blends, Rheol. Bull 67 (1) (1998) 5-8.

[28] C. Dae Han, J. K. Kim, On the use of time-temperature superposition in multicomponent/multiphase polymer systems, Polymer 34 (12) (1993) 2533-2539.

[29] L. Rouleau, J.-F. Deü, A. Legay, F. Le Lay, Application of KramersKronig relations to timetemperature superposition for viscoelastic materials, Mechanics of Materials 65 (2013) 66-75.

[30] J. Dealy, D. Plazek, Time-temperature superposition, a users guide, Rheol. Bull 78 (2) (2009) 16-31.

[31] R. Beblo, L. M. Weiland, Strain induced anisotropic properties of shape memory polymer, Smart Materials and Structures 17 (5) (2008) 055021. 
[32] A. J. McClung, G. P. Tandon, J. W. Baur, Strain rate-and temperaturedependent tensile properties of an epoxy-based, thermosetting, shape memory polymer (veriflex-e), Mechanics of Time-Dependent Materials 16 (2) (2012) 205-221.

[33] T. Pritz, Frequency dependences of complex moduli and complex poisson's ratio of real solid materials, Journal of Sound and Vibration 214 (1) (1998) $83-104$.

[34] N. W. Tschoegl, W. G. Knauss, I. Emri, Poisson's ratio in linear viscoelasticity-a critical review, Mechanics of Time-Dependent Materials $6(1)(2002) 3-51$.

[35] R. J. Allemang, The modal assurance criterion-twenty years of use and abuse, Journal of Sound and Vibration 37 (8) (2003) 14-23.

[36] M. L. Williams, R. F. Landel, J. D. Ferry, The temperature dependence of relaxation mechanisms in amorphous polymers and other glassforming liquids, Journal of the American Chemical Society 77 (14) (1955) 3701-3707.

[37] J. Seitz, C. Balazs, Application of time-temperature superposition principle to long term engineering properties of plastic materials, Polymer Engineering \& Science 8 (2) (1968) 151-160.

[38] L. Strum, Physical aging in plastics and other glassy materials, Polymer Engineering \& Science 17 (3) (1977) 165-173.

[39] E. S.-W. Kong, G. L. Wilkes, J. E. McGrath, A. Banthia, Y. Mohajer, 
M. Tant, Physical aging of linear and network epoxy resins, Polymer Engineering \& Science 21 (14) (1981) 943-950.

[40] W. Cook, M. Mehrabi, G. Edward, Ageing and yielding in model epoxy thermosets, Polymer 40 (5) (1999) 1209-1218. 